\title{
Self-organization of the Student Body: Social Order and Realities
}

\author{
Natalia Vitalievna Shmurygina \\ Natalia Gennadievna Bazhenova \\ Ruslan Ivanovich Bazhenov \\ Ekaterina Leonidovna Lutsenko \\ Olga Leonidovna Konovalenko
}

Sholom-Aleichem Priamursky State University, Russian Federation, 679015, Birobidzhan, Shirokaya Street, 70a

\author{
Doi:10.5901/mjss.2015.v6n5s1p502
}

\begin{abstract}
The paper presents an analysis of methods of the creation of student associations on the basis of self-organization, which is an opportunity for young people to correct and develop the personal potential within educational institutions. The aim of this study is to determine the characteristics of self-organization process through the analysis of student association's life, the assessment of real practices on the development of self-organizing processes by student associations, revealing contradictions and conditions "hindering" the development of this process in educational institutions. As a result, it was found that the correlation of personal qualities of the students, the community of participation motifs and the community of the value base for the organization of a productive life activity of the association can be attributed to them. The highlighted regulations are the basis and guidelines of building effective work of the relevant departments and services of the university.
\end{abstract}

Keywords: self-organization, student body, youth, values

\section{Introduction}

In the modern period in connection with the fundamental socio-economic, political and socio-cultural changes taking place in a situation of ambiguity and social risks, the implementation of the social role of young people directly depends on the interested and targeted policy of the state to ensure the effectiveness of all social institutions. The precarious situation of the students in education, employment problems - are often accompanied by anxiety about their future, sometimes getting destructive forms (alcoholism, drug addiction, etc.). Technologies and failures in the system of state education has led to an increase in illiteracy, unemployment, social dependency, racial tensions, crime and other social problems (Roueche \& Roueche, 1999).

The main goal of education today - is to prepare a qualified employee with an appropriate level and profile, who is competitive on the labor market, competent, responsible, and able to work effectively on his specialty at international standards, ready for continuous professional growth, social and professional mobility to better work in the future. One of the conditions for a full active social development of the individuality of the future specialist is to provide various forms of collective self-organization, implemented in the creation of student associations that aim to personality development, to the acquisition of social experience (Porta \& Diani, 2006; Stuart et al., 2011). In practice, self-organization of the students did not always receive adequate manifestation, and the students' associations initiated by the top do not always represent the interests of self-organization of the students (Fuchs, 2006). Creating students' associations by self-organization for youth is an ability to correct and develop not only their personal potential (value, motivational base, a sufficient level of development of personal qualities), but also to use the associations' potential to solve the problems of social character (Hanson, 2014; Hasan et al., 2010).

Currently, in the universities there are a large number of student associations of various forms, ranging from officially registered trade union organization, and ending with small youth groups, which are informal, created at the level of faculty or course. Increasing the number of associations points to the fact of readiness of the students to an organized cooperation for the realization of their interests and needs. Ignoring this fact today is not possible. For a more effective and efficient interaction with the youth there is a need for additional understanding of the purpose, methodological 
foundations and semantic content of students' organizations (Roueche \& Roueche, 1999).

The processes of creating students' associations should be aimed at giving them social and practical character, because of the need of conscious, responsible attitude of the students to the possibilities and prospects of their professional, cultural and moral self-organization and participation in the social management (Finn \& Zimmer, 2012). Insufficient consideration of the development of self-organization processes and their impact on improving trunking of the students has necessitated this study among students.

\section{Method}

The main methods of achieving the objectives in the context of the problem being studied are: a review and analysis of the sources (Crotty, 1998), devoted to the study of self-organization process of the student body, as well as empirical data on the results of the studies on the existing problems (Singleton Jr. \& Straits, 2010). At the first stage we used the method of observation, with which we managed to get the initial information on the studied problem in educational institutions (Bryman, 2012; Neuman, 2013). Was made a statement of facts - the low activity of the students in the trunking processes on the basis of self-organization, and the existence of practices of creating associations by the administration of the educational institutions. A statistical study was conducted in the form of a sociological survey using the method of analysis, ranking (Matthews \& Ross, 2010). The obtained data in each block were used as indicators of the dependent variables. Survey participants were students of Russian Far Eastern Universities of Birobidzhan, Khabarovsk, Blagoveshchensk in the age from 16 to 22 years, divided according to the types of educational institutions (176 people University students, 100 people - College students). The quoted sign was belonging to the faculty, to the course, gender. The sample was formed in each university individually, randomly at the stage of selecting respondents. Respondents were given a designed questionnaire with open and closed questions, where it was necessary to choose the answer that reflects the position of the subject.

The presented study was aimed to study the characteristics of self-organization process. The questionnaire consists of four blocks. We present the testable hypotheses from relevant units:

\# 1 - knowing the causes, factors (external - that influence the trunking processes (collective self-organization) and internal - influencing the dynamics of intra-group processes (personal self-organization), it is possible to assist the construction of work of students' associations leaders; students in the process of participation and performance of the Group activities and educational organizations in the organization of work with young people;

- \# 2 - the ratio of personal qualities of the people in the team is a prerequisite for purposeful interaction in the group;

- \# 3 - priority factors of personal motivation affect the activity in the union;

- \# 4 - commonality and difference of values are the basis for bringing people together to implement joint goals and vice versa.

\section{Results}

\subsection{Block\# 1. Self-organization, general questions.}

Analyzing student associations as a system, it is necessary to determine the attitude of the students themselves. During the study, the respondents were asked to answer a series of questions about the importance of students' associations.

Analysis of the answers to the question "Why do you think should the students join the organizations?" shows that the main purpose of association for $69 \%$ of the respondents is the desire to expand the circle of friends; $14 \%$ concerned about moral satisfaction; to $10 \%$ - this is a way to avoid loneliness; $4 \%$ want to gain fame; $3 \%$ care about material satisfaction. Community for the students comes to the forefront in connection with the peculiarities of the age. The need to meet this need - the desire to find themselves, their place in the team, to feel like a part of the group - is a motive for joining the union. Communicating in a team, students get the opportunity to find friends, the necessary connections, as well as the possibility to develop or modify the existing personal qualities, skills. In evaluating the reasons for trunking we can trace the prevalence of personal motivation, aimed at obtaining personal skills of self-organization, self-development, self-education, the desire to get the necessary social experience.

The analysis of the answers to the question aimed at identifying the main principles of the students' associations, allowed to identify the following ratio: common interests- $64 \%$; joint activities - $35 \%$, high activity - $11 \%$. Being an objective motivation, a desire of the individual, common interests operate only through various forms of human activity, 
speaking as a motivating force for a purposeful and practical activity. Thus, a joint activity is a consequence of a harmonious combination of common interests in the process of awareness, acceptance and achieving the goals in a collective unity based on a productive performance of tasks.

At a time when one of the important elements of development, correcting and formation of the individuality is the students' association, we are seeing a low percentage of the activity of students - among all the surveyed students, only $25 \%$ are in the students' union (some students are parts of many associations at a time), $75 \%$ students are not a part of any.

The results of further study of students' opinions who are not in unions, showed that $19 \%$ of respondents "would like to belong to an organization"; $37 \%$ "do not like to" - ; "This desire sometimes appears briefly" - 31\%; "I would like to, but I do not know where to go" - 13\%. You may notice that a potentially active "reserve" may be the students with a clear desire to join a Students' Society ("yes"), but for some external or internal reasons they still do not do so, with not clearly defined motifs ("the desire arises sometimes briefly"), with the problem of information literacy (" I do not know where to go "). The obtained data indicate activities requiring close attention, deep study and discussions at all levels - from the university administration, services, working with young people to student organizations.

Analysis of the data on the question, "What's stopping you to join a students' association?" made it possible to identify the main obstacles: "lack of time due to work," noted by $35 \%$ of the respondents (early employment of the students reduces the chances to demonstrate their activity in students' associations, time resource); "None of my friends is there, and I do not want to go" - 22\% (significance of the reference group in the selection of a particular activity); "I do not know where to go" - 30\% (the problem of a lack of information to be involved in the activity); "A large number of strangers" - 13\%. These indicators point to a lack of time, information, human and material resources for the students, and this in turn leads to a decrease in productive activities that give results. In the phenomenon of self-organization, the study of human resources in the social system, has a specific character: not so much through quantitative indicators, but through relationships (collective self-organization), through the formation of a new quality (personal self-organization).

Analysis of students' associations revealed the predominance of social orientation - $30 \%$, creative $-21 \%$, scientific - $10 \%$, others $-39 \%$. On the question of choosing the priority activity of the students' associations extracurricular activities was noted in 59\% of the respondents (organization and implementation of extra-curricular activities: development and implementation of the projects - $24 \%$ protection of the rights and interests of students, $15 \%$, others - 20\%). A wide range of activities of the associations gives a choice, but the prevalence in the activity of only a creative orientation can be an obstacle for showing the activity for the category of students who do not consider them to be creative.

From the main purposes of students' organizations at the university, we identified important landmarks in their activities: participation in various processes of the institution - 30\%; good public affairs - 25\%; creating a positive image of the university in the city - $20 \%$ protection of the interests of the students - $20 \%$; others - $5 \%$. Considering the associations as a real force for solving problems in the quality of training of the specialists, the administration of the educational institutions should pay more students' attention to the importance and the prospect of the participation in the association as a launching pad for the development of their personality, raising the educational level, obtaining the proper knowledge and skills.

In the process of analyzing the obtained data we have made a number of conclusions on the features of selforganization processes:

Identical motifs enhance individual and collective self-organization;

The ratio of personal qualities helps or hinders the Group Forming (collective self-organization);

The commonality and difference of values are the basis for the association;

Lack of resources in human decreases his activity in the learning process and beyond it.

The obtained results correlate with the selected ones during the theoretical study of the scientific literature features of self-organization process. Further research suggests a more detailed study of each of the selected feature.

\subsection{Block\# 2 - Features of the process of self-organization in the context of personal qualities.}

The ratio of personal qualities of people in the team is a prerequisite for a purposeful interaction in the group, so you need to pay attention to the importance of this factor. To the question "How do you feel about other people's shortcomings" $50 \%$ of the students answered "tolerant", $27 \%$ - "indifferent", $20 \%$ - "do not paying attention", $3 \%$ - "other". Tolerant attitude towards other people's shortcomings gives the ability to suggest some degree of awareness in relation to the manifestations of other people, a correct understanding of certain actions. Indifference and lack of attention to the shortcomings of others may reflect a certain degree of disinterest, isolation and which are possible, difficulties in interaction with other people. 
Analysis of the questions, directed to the allocation by the respondents of three positive and three negative qualities of today's students, it is presented in Table 1 (it gives the qualities of the highest rating, we had the opportunity to mention some of them) (Table. 1).

Table 1: Positive and negative qualities of today's students

\begin{tabular}{|l|l|}
\hline Positive qualities & Negative qualities \\
\hline Activity - $64 \%$ & Laziness - 79\% \\
\hline Creativity - 57\% & Indifference - 49\% \\
\hline Initiative - 44\% & Optionality - 39\% \\
\hline
\end{tabular}

On the one hand, the presence of positive qualities in students is increasingly expected to contribute to the manifestation of positive "effect of self-organization," hindrance" in this case is a set of opposite qualities. In a provided good compatibility of the qualities of the person (personal self-organization) optimal conditions are created for the implementation of the activities in the collective (collective self-organization).

In identifying the tendency of students in the performance of some activity, we obtained the following results: $27 \%$ of the respondents willing to manufacture, $27 \%$ - to implement; $21 \%$ - to lead; $18 \%$ - to create, $17 \%$ - other. The choice of activities is associated with the internal development conditions, which are formed in the process of human interaction with the outside world. For example, a successful teamwork supposes a separation of powers, but a unity in the separation of powers cannot arise by chance, it arises in the course of competent actions of the leader with pronounced individual features.

Analysis of the evaluation of their own resources in carrying out activities, getting a job alone, showed that $60 \%$ of students will finish the received job, $23 \%$ are not sure, $15 \%$ will finish, but they will not do anything else then; $2 \%$ - will not cope. Resources are a set of certain qualities of the subject, determining their ability to work, the desire to a productive result of work, which is reflected in the entire association. In the proper degree the developed personal qualities of the students will allow them to cope with the assumed obligations, to bring tasks to the end. $15 \%$ of students who will finish the task "will finish, but will not do anything else then" they have to become an object of attention of psychological services of the institutions keeping the contingent among the "active ones".

The ratio of personal qualities of a person in an organized group, is a condition of their purposeful interaction. If the students show a complete incompatibility of the qualities between the individuals, then it is impossible to get the effectiveness of the activities, and this can lead to the disintegration of the group. And, vice versa, in case of good compatibility, there are optimal conditions for the life of the association. As a result of the interaction of all the constituent elements of the organization, there is a positive or negative effect of self-organization, especially if the structural elements disagree with each other, there is a negative synergetic effect, if they are adequate -a positive effect. The effect of selforganization is possible by increasing the effectiveness of synergies, including a variety of personal qualities in the process of implementation of the relevant activities.

\subsection{Block\# 3 the study of the process of self-organization in the context of students' motivation.}

Analysis of the attitude of the respondents to the students' groups should be determined by allocating the priority factors of personal motivation. Participants of the organizations (25\% of all respondents), $96 \%$ of them entered the association deliberately and voluntarily. The main motifs were identified (it was possible to select multiple options): "to gain experience for future professional activity" - 45\%; "Benefit the society" - 43\% (taking into account the priority activities of students' organizations - public); "Like to participate in group affairs" - 36\%; "Just to do something besides studying" 26\%; "Material benefit" - 6\%; "I want to get an approval and praise from the leadership" - 3\%. The survey's results show the direction, primarily on personal development, and then the social and status motives. Without taking into account the motives which are considered by a person in a certain activity, in the implementation of the objectives it is impossible to understand social actions, social relationships and interactions committed in the implementation of the goal. Conscious motives increase personal self-organization.

Motif - is an incitement to commit a behavioral act, generated by a system of human's needs and with varying degrees is understood or not by him. In the process of committing behavioral acts, the motives, as dynamic entities, can be transformed (changed), which is possible in all phases of the action, and the behavioral act often ends not at the original but at the transformed motivation (Alsted, 2005). Analysis of responses to the question about the ability to always describe the behavior motives showed that $40 \%$ of respondents do it; $30 \%$ of respondents sometimes do not think about 
them; $23 \%$ - no; $7 \%$ - never think about it.

To the question "Does your motives change in the participation in a particular case of the students' union?" Indicates from case to case to a change of $52 \%$ of the respondents; no - 25\%; Yes - 19\%; always changing - 4\%. On the one hand, the formation of motivation and self-organization of the students is accompanied by changes in selforganization (the development, correction of personal qualities). On the other hand, a specific motive is not uniquely determining the motivation of the activity, it is necessary to take into account the contribution of the factors of a specific situation.

Self-organization and motivation are linked, since the mechanism of motivation, is subject to the logic of a real human experience, and to the logic of self-development of the human, who is actively building his own motivational sphere. Self-organization processes will proceed faster if there are conditions for the development incentive motivational aspects, fixing the internal positive motifs. The process of accounting the motivations is difficult, studying the determining impact on people's attitudes toward work, assessing a specific situation, taking into account the reasons that caused it, could lead to an increase in collective self-organization.

\subsection{Block \# 4 studying the process of self-organization in the context of the study of the value base of the students.}

Similarities and differences of values are the basis for bringing people together to implement joint goals and vice versa.

M.Rokeach highlights two classes of values - terminal and instrumental. Terminal values M.Rokeach defines as a belief in that some ultimate goal of individual existence (e.g., happy family life, peace in the world) from personal and social points of view worth to be strived for; instrumental values - as beliefs in that certain actions (e.g., honesty, rationalism) are preferred in all situations from personal and social perspectives. In fact, the dilution of terminal and instrumental values produces a traditional distinction between values- goals and values-means (Rokeach, 1973).

As a result, priority values - goals with the highest percentage we allocated (it was possible to select multiple options): health (physical and mental) - 64\%; happy family life - 51\%; the existence of good and faithful friends - 36\%; financially secure life - $30 \%$ (this figure is not among the top three values). These values refer to the guidelines in life that need no justification, and are important in them. The obtained data is related to the trends described in contemporary sociological researches in the field of values of young people identifying family, health and friends as a priority.

Values-means were reported in the following proportions (it was possible to select multiple options): honesty $55 \%$; responsibility - 40\%; humorous - 33\%. They embody a certain situational goal; serve as a means to achieve other important goals. Values- goals and values- means must be consistent with each other for the harmony of the individual.

In the course of the study the students were asked "What do you personally get or will get from the participation in a students' organization?" Responses indicate that a priority importance can be given to (it was possible to select multiple options): the ability to self-realization - 88\%; the development of professional skills, required in the future - $51 \%$; moral satisfaction - 51\%; recognition and financial reward - 36\%. The analysis allows us to observe the prevalence of the internal personal motivation when joining a students' association aimed at increasing their own level of development. This commitment reflects the youth problems present in today's society - fear of being left unclaimed, unsustainable trends in the employment of graduates in the labor market, looking for prospects, and so on.

\section{Discussion}

The obtained results underlined the provability of the hypotheses suggested by us. Today, students' associations are a real force for personal development, including the development of self-organization processes - personal and collective. Studying the peculiarities of the process of self-organization of the students in the context of studying personal qualities, is of interest within studying the properties, characteristics and qualities of the subjects, which by their nature are formed in the course of human relations, they are manifested in them and have an impact on the emergence of new relations and certain types of interaction.

Analysis of the obtained data in the study showed the presence of a proper degree of students' associations of different directions more focused on social activities. The process of personality formation occurs in the activity through the implementation of various activities (Eccles \& Barber, 1999). The degree of participation of young people in the groups depends on voluntariness of entering them, the formation of group consciousness, and the presence of social participation experience in the past. The identification of such factors will help in the formation of a responsible attitude of the students to self-development, taking into account the possibilities and prospects in their future professional selforganization and participation in the management of educational institutions. Participation in the activities of the association has a beneficial effect on the formation of creative and independent personality of young specialists. Studying 
the desire and ability to Group Forming will help to acquire the qualities needed in a changing society.

A number of studies in the field of students' motivation to perform a particular activity, to participate in the affairs of the students' association showed that it largely consists of determining the degree of importance for the student himself, common interests, the desire to self-development, self-realization, self-knowledge (Gao, 2008; Granger, 2014; NikkarEsfahani et al., 2012; Osteen, 2011).

As a result of the study, the stimulating activities are motives aimed at obtaining social experience, selfdevelopment, a desire to communicate, to benefit people, the desire to be noticed by managers.

Through the analysis of the obtained data and the existing results of other studies it is clear that personal motives come to the fore (personal development), and then the social-status motives. Such manifestations reflect the aspirations of young people to develop the necessary elements of the personality, to overcome the difficulties in the process of search for future place of employment, the adaptation in a team, etc.

In the educational institutions we should create conditions for the intersection of personal and professional motifs, in the components of the curriculum, management strategies, within the frameworks of the formation of a conscious choice, meaningful in accordance with their motivation. This can be realized in practice, in the participation in students' associations.

Formation of self-organization and motivation in students is accompanied by changes:

In the field of self-organization - the mobilization of resources to achieve the goals, planning, restructuring of the senses, the development of team working skills;

In the field of motivation - the perseverance level, the volume of done work, the made effort, activity, choice of activities, etc.

Within studying the characteristics of self-organization value orientations represent the principle of system determination that helped to overcome internal and external opposition by defining a specific individual space.

Crisis of values in modern society is reflected in the education system (Goetz, 2014), when there is a predominance of liberal values over the democratic and public ones in the society. A number of studies in this area have shown the prevalence of values in education, to acquire social status (Moosmayer \& Siems, 2012), the value of the performed professional work. Such values as health, family, friends, are below in the rank.

Analysis of the results of the research indicates an opposite ranking in the order of importance of values: 1) health; 2) family; 3) faithful friends; 4) financially secure life. Assessing the degree of conformity of the selected values from the study of different levels we can talk about the coincidence of the values of "leaders", the only difference is in the rank order of importance.

The indicated in the study list of features does not claim to uniqueness and perfection -it is the primary drafts guidelines that require further reflection, replenishment, reconciliation and experimental testing. The highlighted features of self-organization process are the basis and guidelines of building an effective work of the relevant departments and services of the university for maintenance, revitalization and promotion of these processes. Work without taking into account the dedicated features and factors is not productive, not systematic and often "in idle".

\section{Conclusion}

The article presents an analysis of the current state of the question of self-organizational processes in educational institutions. Based on analysis of current scientific literature and empirical research we identified features of the process of self-organization affecting the trunking processes among students.

Summarizing we can say that a directed synthesis of the existing university services of the area in promoting the process of collective self-organization will help to meet the needs of the transition of the state of uncertainty, dependence to the state of confidence, social maturity. This problem is one of the most important tasks, since the main purpose of education is to prepare professionals, personal growth of the students, development of social skills, social adjustment skills, etc.

Directions for further research can be:

- in terms of theoretical study - further deepening and expansion of scientific research in the context of the theme;

- In terms of the empirical component - conducting a survey for a deep studying of the selected features in all educational institutions of the city, in order to conduct a comparative analysis, of the importance of the features in the context of an educational institution, training areas, and the course. Also studying the individual characteristics of the process of self-organization based on certain personality types.

One of the areas of practical work that promotes the self-organization of students in high school is the introduction 
and use of a specialized program that will contribute to the development of self-organization by artificially changing in the elements of social systems, taking into account the external environment, which is a regulator of the necessary connections of the external manifestations of the students.

\section{References}

Alsted, J. (2005). A model of human motivation for sociology. New York: P. Lang. ISBN 978-3-631-52907-2

Bryman, A. (2012). Social research methods (4nd ed.). Oxford: Oxford University Press. ISBN 978-0-19-958805-3

Crotty, M. (1998). The foundations of social research: Meaning and perspective in the research process. London: Sage Publications. ISBN 0-7619-6105-4

Eccles, J. S. \& Barber, B. L. (1999). Student Council, Volunteering, Basketball, or Marching Band: What Kind of Extracurricular Involvement Matters?. Journal of adolescent research, 14(1), 10-43. Retrieved from http://dx.doi.org/10.1177/0743558499141003

Finn, J. D., \& Zimmer, K. S. (2012). Student engagement: What is it? Why does it matter?. In Handbook of research on student engagement (pp. 97-131). Springer US, Retrieved from http://dx.doi.org/10.1007/978-1-4614-2018-7_5

Fuchs, C. (2006). The self-organization of social movements. Systemic practice and action research, 19(1), 101-137. Retrieved from http://dx.doi.org/10.1007/s11213-005-9006-0

Gao, Z. (2008). College students' motivation toward weight training: A combined perspective. Journal of Sport Behavior, 31(1), $22-43$.

Goetz, D. (2014). The Effects of an Academic Values Clarification Exercise on Academic Performance of College Students (Honors Theses). Western Michigan University. Retrieved from http://scholarworks.wmich.edu/honors_theses/2427

Granger, C.J. (2014). The influence of extracurricular activities on student performance perceived by texas rural high school principals with successful extracurricular programs (Ed.D.). Lamar University - Beaumont.

Hanson, C. (2014). In Search of Self: Exploring Student Identity Development: New Directions for Higher Education, Number 166. San Francisco, California: Jossey-Bass. ISBN 978-1-118-91508-0

Hasan, S., Crocker, R., Rousseliere, D., Dumont, G., Hale, S., \& Srinivas, H. et al. (2010). Self-organization. International Encyclopedia Of Civil Society, 1364-1370. Retrieved from http://dx.doi.org/10.1007/978-0-387-93996-4_87

Matthews, B., \& Ross, L. (2010). Research methods: A practical guide for the social sciences. New York, NY: Pearson Longman. ISBN 9781405858502

Moosmayer, D., \& Siems, F. (2012). Values education and student satisfaction: German business students' perceptions of universities' value influences. Journal Of Marketing For Higher Education, 22(2), 257-272. Retrieved fromhttp://dx.doi.org/10.1080/0884 1241.2012.746254

Neuman, L. (2013). Basics of Social Research: Pearson New International Edition Qualitative and Quantitative Approaches. (3rd ed., international ed.). Harlow: Pearson. ISBN 9781292020341

Nikkar-Esfahani, A., Jamjoom, A. A., \& Fitzgerald, J. E. F. (2012). Extracurricular participation in research and audit by medical students: opportunities, obstacles, motivation and outcomes. Medical teacher, 34(5), e317-e324. Retrieved from http://dx.doi.org/10.3109/ 0142159X.2012.670324

Osteen, P. (2011). Motivations, values, and conflict resolution: students' integration of personal and professional identities. Journal Of Social Work Education, 47(3), 423-444. Retrieved from http://dx.doi.org/10.5175/jswe.2011.200900131

Porta, D., \& Diani, M. (2006). Social movements an introduction (2nd ed.). Malden, MA: Blackwell. ISBN 978-1-4051-4821-4

Rokeach, M. (1973). The nature of human values. New York: The Free Press.

Roueche, J., \& Roueche, S. (1999). High stakes, high performance: Making remedial education work. Washington, D.C.: Community College Press. ISBN-0-87117-321-2

Singleton Jr, R. A., \& Straits, B. C. (2010). Approaches to social research. New York: Oxford University Press. ISBN 0-1953-7298-0

Stuart, M., Lido, C., Morgan, J., Solomon, L., \& May, S. (2011). The Impact Of Engagement With Extracurricular Activities On The Student Experience And Graduate Outcomes For Widening Participation Populations. Active Learning in Higher Education, 12(3), 203-215. Retrieved from http://dx.doi.org/10.1177/1469787411415081 